\title{
The effect of inhaling a dry powder of sodium chloride on the airways of asthmatic subjects
}

\author{
S.D. Anderson*, J. Spring*, B. Moore**, L.T. Rodwell*, N. Spalding*, \\ I. Gonda+, K. Chan+, A. Walsh+, A.R. Clark+
}

The effect of inhaling a dry powder of sodium chloride on the airways of asthmatic subjects. S.D. Anderson, J. Spring, B. Moore, L.T. Rodwell, N. Spalding, I. Gonda, K. Chan, A. Walsh, A.R. Clark. (C) ERS Journals Ltd 1997.

ABSTRACT: Wet aerosols of $4.5 \%$ sodium chloride $(\mathrm{NaCl})$ are often used to assess the bronchial responsiveness associated with asthma. We questioned whether dry $\mathrm{NaCl}$ could be used as an alternative.

Dry powder $\mathrm{NaCl}$ was inhaled from capsules containing either $5,10,20$ or 40 mg to a cumulative dose of $635 \mathrm{mg}$. The powder was delivered via an Inhalator ${ }^{\mathrm{TM}}$ or Halermatic ${ }^{\mathrm{TM}}$. The airway sensitivity to the dry and wet $\mathrm{NaCl}$ was compared in 24 patients with asthma aged 19-39 yrs.

All subjects responded to both preparations and the geometric mean $(95 \%$ confidence intervals) for the provocative dose of $\mathrm{NaCl}$ causing forced expiratory volume in one second (FEV1) to fall $20 \%$ from baseline $(\mathrm{PD} 20, \mathrm{NaCl})$ for dry $\mathrm{NaCl}$ was $103 \mathrm{mg}(68-157)$ versus $172 \mathrm{mg}(102-292), \mathrm{p}<0.03$ for the wet $\mathrm{NaCl}$. The response to dry $\mathrm{NaCl}$ was reproducible and on repeat challenge the PD20 was $108 \mathrm{mg}$ (75-153). The mean maximum fall in FEV1 was approximately $25 \%$ on each of the two test days. Spontaneous recovery occurred within $60 \mathrm{~min}$ after challenge with dry $\mathrm{NaCl}$ and within 5 min after bronchodilator. There were no serious sideeffects requiring medical attention, however some patients coughed on inhalation of the $40 \mathrm{mg}$ dose and three gagged. Arterial oxygen saturation remained within normal limits.

We conclude that a suitably prepared dry powder of sodium chloride could potentially replace wet sodium chloride to assess bronchial responsiveness in patients with asthma, but further studies are required to establish the long-term stability of the dry powder preparation.

Eur Respir J 1997; 10: 2465-2473.
*Dept of Respiratory Medicine PCP9, Royal Prince Alfred Hospital, Camperdown, NSW, Australia. **St Pauls Hospital, Vancouver, Canada. ${ }^{+}$Genentech Inc, South San Francisco CA, USA.

Correspondence: S.D. Anderson Dept of Respiratory Medicine

PCP9, Royal Prince Alfred Hospital

Missenden Road

Camperdown

NSW 2050

Australia

Keywords: Asthma, bronchial provocation, dry powder, osmotic challenge, sodium chloride

Received: February 121997

Accepted after revision August 191997

The major funding for this study came from the National Health and Medical Research Council of Australia (JS, LTR) with small grants from the Asthma Foundation of NSW, Boehringer Ingelheim Pty Ltd, Sydney, NSW, Australia (NS) and Genentech Inc, So San Francisco CA, USA.

A patent has been registered internationally for the use application described in this study, PCT/AU 95/00086.
Bronchial provocation testing, is well established as a technique for identifying and assessing the severity of airway hyperresponsiveness in persons suspected of having asthma [1]. In 1981, SchoefFEL et al. [2] reported that patients with asthma were sensitive to the inhalation of wet aerosols of hypotonic and hypertonic saline. This observation led to the development of a standardized bronchial provocation challenge with hypertonic saline both in adults and children [1,3-8]. Studies comparing responses to hypertonic saline and other provocative stimuli commonly used for bronchial provocation testing have shown good concordance between responses to hypertonic saline, exercise and hyperventilation [9-11]. Patients responsive to hypertonic saline have been shown to have bronchial hyperresponsiveness to inhaled aerosols of methacholine and histamine with a $20 \%$ fall in forced expiratory volume in one second (FEV1) at concentrations $<8 \mathrm{mg} \cdot \mathrm{mL}^{-1}$ or a dose $<4 \mu \mathrm{mol}$ [5].

There are, however, disadvantages when using wet aerosols of hypertonic saline. An ultrasonic nebulizer is needed and this requires maintenance and cleaning. Furthermore, a weighing machine is needed to measure the output for each challenge test as output differs over time, between nebulizers, and between patients. Another disadvantage, as with other wet aerosols, is that the person administering the test is also exposed to the aerosol. For these reasons we investigated the possibility that a dry powder preparation of sodium chloride $(\mathrm{NaCl})$ could be substituted for the wet aerosol preparation of $4.5 \%$ $\mathrm{NaCl}$.

The aim of this study was to compare the airway sensitivity to a suitably prepared dry powder inhalation of $\mathrm{NaCl}$ with that of an inhaled wet aerosol preparation of $4.5 \% \mathrm{NaCl}$ in patients known to be responsive to challenge with hypertonic saline. The reproducibility of the airway responses to the dry powder and the time-course of spontaneous recovery of the airways after challenge were also investigated.

\section{Subjects}

Twenty four asthmatic subjects (seven males and 17 females) aged 19-39 yrs, were recruited from the local community (table 1). All subjects had a baseline FEV1 
Table 1. - Anthropometric details

\begin{tabular}{|c|c|c|c|c|c|c|c|c|c|c|}
\hline \multirow[t]{2}{*}{$\begin{array}{l}\text { Subj. } \\
\text { No. }\end{array}$} & \multirow{2}{*}{$\begin{array}{l}\text { Age } \\
\text { yrs }\end{array}$} & \multirow[t]{2}{*}{ Sex } & \multirow{2}{*}{$\begin{array}{l}\text { Height } \\
\text { cm }\end{array}$} & \multirow{2}{*}{$\begin{array}{c}\text { Predicted } \\
\text { FEV1* } \\
\text { L }\end{array}$} & \multirow[t]{2}{*}{$\begin{array}{c}\text { Daily } \\
\text { medication }\end{array}$} & \multirow{2}{*}{$\begin{array}{l}\text { Dose ICS } \\
\mu \mathrm{g} \cdot \text { day }^{-1}\end{array}$} & \multirow[t]{2}{*}{ Atopic } & \multirow{2}{*}{$\begin{array}{l}4.5 \% \\
\text { saline } \\
\text { Control } \\
\text { PD20 } \\
\text { mg }\end{array}$} & \multicolumn{2}{|c|}{$\begin{array}{l}\text { Dry } \mathrm{NaCl} \\
\text { challenge }\end{array}$} \\
\hline & & & & & & & & & $\begin{array}{c}1 \\
\text { PD20 } \\
\text { mg }\end{array}$ & $\begin{array}{c}2 \\
\mathrm{PD} 20 \\
\mathrm{mg}\end{array}$ \\
\hline 1 & 27 & $\mathrm{~F}$ & 160 & 3.05 & Sal p.r.n. & & Yes & 296.1 & 73.7 & 172.1 \\
\hline 2 & 29 & $\mathrm{~F}$ & 159 & 2.96 & Sal p.r.n. & BDP 400 & Yes & 32.85 & 22.1 & 111.8 \\
\hline 3 & 25 & M & 188 & 4.87 & Fen 800 & BDP 1000 & Yes & 7.2 & 50.1 & 18.2 \\
\hline 4 & 19 & $\mathrm{~F}$ & 161 & 3.13 & Sal p.r.n. & Bud 1600 & Yes & 163.35 & 67.2 & 151 \\
\hline 5 & 39 & M & 172 & 3.78 & Sal p.r.n. & BDP 100 & Yes & 955.8 & 107.7 & 103.8 \\
\hline 6 & 22 & $\mathrm{~F}$ & 167 & 3.37 & Sal p.r.n. & Bud 2400 & Yes & 99.9 & 168.2 & 138.22 \\
\hline 7 & 29 & $\mathrm{~F}$ & 169 & 3.35 & Sal p.r.n. & Bud 800 & Yes & 45.9 & 105.6 & 55.08 \\
\hline 8 & 22 & $\mathrm{~F}$ & 176 & 3.73 & Sal p.r.n. & Bud 800 & Yes & 378 & 151.5 & 56.39 \\
\hline 9 & 29 & M & 189 & 4.8 & $\begin{array}{l}\text { Fen } 0.4 \mathrm{mg} \\
\text { p.r.n. }\end{array}$ & & - & 651.15 & 146 & 127 \\
\hline 10 & 20 & F & 157 & 2.98 & Sal $600 \mu \mathrm{g}$ & Bud 800 & Yes & 149.4 & 161 & 96 \\
\hline 11 & 23 & $\mathrm{~F}$ & 166 & 3.33 & $\begin{array}{l}\text { Sal } 100 \mu \mathrm{g} \\
\text { p.r.n. }\end{array}$ & & & 295.2 & 155 & 162 \\
\hline 12 & 21 & F & 167 & 3.37 & $\begin{array}{l}\text { Sal } 200 \mu \mathrm{g} \\
3-4 \text { per week }\end{array}$ & & Yes & 249.75 & 121 & 118 \\
\hline 13 & 21 & M & 191 & 5 & $\begin{array}{l}\text { Sal } 600 \mu \mathrm{g}, \\
\text { Terf } 240 \mathrm{mg}\end{array}$ & & & 508.5 & 423 & 588 \\
\hline 14 & 28 & M & 186 & 4.7 & $\begin{array}{l}\text { Sal } 200 \mu \mathrm{g} \\
3-4 \text { per week }\end{array}$ & & & 232.65 & 126 & 105 \\
\hline 15 & 25 & F & 167 & 3.37 & $\begin{array}{l}\text { Sal } 200 \mu \mathrm{g} \\
\text { p.r.n. }\end{array}$ & & & 153 & 20.45 & 75.69 \\
\hline 16 & 25 & F & 166 & 3.33 & $\begin{array}{l}\text { Sal } 200 \mu \mathrm{g} \\
\text { p.r.n. }\end{array}$ & & & 79.65 & 29 & 40 \\
\hline 17 & 25 & $\mathrm{~F}$ & 163 & 3.21 & Terbutaline & Bud 1200 & & 913.5 & 493.5 & 502.9 \\
\hline 18 & 23 & M & 183 & 4.65 & Sal p.r.n. & & & 725.4 & 36.1 & 79.5 \\
\hline 19 & 25 & $\mathrm{~F}$ & 164 & 3.25 & $\begin{array}{l}\text { Sal } 400 \mu \mathrm{g} \\
\text { and p.r.n. }\end{array}$ & BDP 500 & & 515.25 & 340.7 & 268.6 \\
\hline 20 & 20 & $\mathrm{~F}$ & 158 & 3.02 & $\begin{array}{l}\text { Terbutaline } \\
\text { p.r.n. }\end{array}$ & Bud 800 & & 205.65 & 257.99 & 128.8 \\
\hline 21 & 26 & $\mathrm{~F}$ & 167 & 3.35 & Sal $800 \mu \mathrm{g}$ & BDP 1000 & & 58.5 & 87.93 & 132.03 \\
\hline 22 & 19 & $\mathrm{~F}$ & 151 & 2.74 & Sal p.r.n. & Bud 2000 & & 16.65 & 19.4 & 62.9 \\
\hline 23 & 19 & $\mathrm{~F}$ & 165 & 3.29 & Sal p.r.n. & & & 254.25 & 630 & 283.1 \\
\hline 24 & 24 & M & 181 & 4.57 & $\begin{array}{l}\text { Sal } 600 \mu \mathrm{g} \text {, } \\
\text { Theo } 600 \mathrm{mg}\end{array}$ & BDP 400 & Yes & 137.7 & 52.6 & 19.16 \\
\hline Mean & 24.4 & $\mathrm{~F}=17$ & 169.7 & & & & GM & 172.3 & 102.8 & 108.0 \\
\hline SEM & 0.9 & $\mathrm{M}=7$ & 2.3 & & & & $95 \%$ CI & (101.8- & (67.6- & $(75.2-$ \\
\hline Median & 24.5 & & 167.0 & & & & & 291.7) & 156.5) & 152.8) \\
\hline SD & 4.5 & & 11.2 & & & & & & & \\
\hline Range & 19-39 & & 151-191 & & & & & & & \\
\hline $\mathrm{n}$ & 24 & & 24 & & & & & & & \\
\hline
\end{tabular}

Subj.: subject; FEV1: forced expiratory volume in one second; PD20: provocative dose causing a 20\% fall in FEV1; ICS: inhaled corticosteroid; Fen: fenoterol; Sal: salbutamol; BDP: beclomethasone dipropionate; Bud: budesonide; Theo: theophylline; Terf: terfenadine; 95\% CI: 95\% confidence intervals; GM: geometric mean. *: values are those of QuANJER et al. [15].

$>60 \%$ and a $20 \%$ fall in lung function (FEV1) during challenge with $4.5 \%$ saline. They were all nonsmokers and none had experienced a chest infection in the previous 6 weeks. Subjects were asked to refrain from taking short acting bronchodilators for $6 \mathrm{~h}$ and long acting bronchodilators for $12 \mathrm{~h}$ prior to the study days. No corticosteroids were taken by the subjects on the day of the study and no antihistamines were taken for at least 3 days before the study day. All medications (including the daily dose of inhaled steroids) are recorded in table 1 . The healthy subjects had no personal or family history of asthma, were nonsmokers and did not have a positive skin-test to common allergens (dust, grasses, animal dander, moulds). The study was approved by the Central Sydney Area Health Service Ethics Committee (X93-0061) and all subjects signed a consent form prior to commencement of the study. The study was carried out under the Clinical Trial Notification Scheme of the Therapeutics Goods Administration of Australia (CTN 94-633).

\section{Methods}

\section{$\mathrm{NaCl}$ powder and capsule preparation}

The $\mathrm{NaCl}$ powder (Mallinckrodt AR; Paris, KY, USA) was prepared for inhalation at Genentech Inc (So San Francisco, CA) by the method of micronization using a Trost air impact pulverizer (Trost Equipment Corporation, Newtown, PA, USA). The mill uses compressed nitrogen to break up the $\mathrm{NaCl}$ crystals by collision. Prior to 
milling, all parts of the mill were washed with Mili-Q water (Millipore Corporation, Bedford, MA, USA), rinsed with ethanol, and dried under a stream of compressed nitrogen. $\mathrm{NaCl}$ was then fed to the micronizer and milled. The powder was collected and milled once more. The powder was then dried in a vacuum oven at $140^{\circ} \mathrm{C}$ and a $5.05 \mathrm{kPa}(38 \mathrm{mmHg})$ vacuum for $1 \mathrm{~h}$, followed by transfer to glass vials and shipment to Sydney. The particle size was measured using a multi-stage liquid impinger (Astra Draco, Lund, Sweden) and by measuring sodium and chloride content by flame photometry on each stage of the impactor. The Halermatic ${ }^{\mathrm{TM}}$ device (Fisons Pharmaceuticals, Loughborough, UK) used was loaded with $120 \mathrm{mg}$ of $\mathrm{NaCl}(3 \times 40 \mathrm{mg}$ capsules) and, by using a pump, a flow rate of $60 \mathrm{~L} \cdot \mathrm{min}^{-1}$ was generated through the device. The particle size analysis was repeated for the Halermatic ${ }^{\mathrm{TM}}$ device and performed for the first time with the Inhalator ${ }^{\mathrm{TM}}$ (Boehringer Ingelheim Pty Ltd., Ingelheim, Germany) after transport of the $\mathrm{NaCl}$ to the Sydney laboratory. The same type of multistage liquid impinger was used as in California, but the sodium and chloride content was measured at each stage using a vapour pressure osmometer (5500 Vapour Pressure Osmometer; Wescor Inc., UT, USA). The bioburden analysis was carried out by Northview Pacific Laboratories Inc (Berkeley, CA, USA). The results for both yeast and mould showed a value of less than 10 colony-forming units $(\mathrm{CFU}) \cdot \mathrm{g}^{-1}$ and no coliforms or other pathogens were detected. The gelatine capsules (No. 2; Gallipot, St Paul, Minnesota, USA) were hand-filled with 5, 10, 20 and $40( \pm 0.2) \mathrm{mg}$ on an analytical balance (BA11OS; Sartorius, Gottingen, Germany) as required under controlled conditions (relative humidity $40 \%$, temperature $20 \pm 1^{\circ} \mathrm{C}$ ) in Sydney. The capsules were held in plastic containers that were stored in a larger glass container with silica gel and kept in a cool environment.

\section{Delivery device}

Two devices were used to deliver the $\mathrm{NaCl}$ powder. Subjects No. 1-8 received the NaCl powder via an Inhalator $^{\mathrm{TM}}$ (Boehringer Ingelheim Pty Ltd) and subjects No. 9-24 received the $\mathrm{NaCl}$ powder via a Halermatic ${ }^{\mathrm{TM}}$ (Fison's Pharmaceuticals Pty Ltd). Both the Halermatic ${ }^{\mathrm{TM}}$ and the Inhalator ${ }^{\mathrm{TM}}$ are single dose devices permitting different doses to be loaded during the challenge. These devices were chosen as they were readily available and many of their delivery characteristics are known [1214].

\section{Flow measurement}

For the Halermatic ${ }^{\mathrm{TM}}$ the subjects were required to inhale the $\mathrm{NaCl}$ powder at a flow rate between $50-120$ $\mathrm{L} \cdot \mathrm{min}^{-1}$. As the design of the Halermatic ${ }^{\mathrm{TM}}$ precludes the in-line measurement of flow at each inhalation, a pressure transducer (DTX Disposable Pressure Transducer; Viggo-Spectromed Oxnard, CA, USA) was used to approximate flow changes. To calibrate the pressure transducer flows of 50-120 L.min ${ }^{-1}$ were generated through a rotameter (Series 2000, GEC-Elliott, Croydon, $\mathrm{UK}$ ) in line with the Halermatic ${ }^{\mathrm{TM}}$ device which was used to deliver the powder. Pressure changes were measured through a side port of the Halermatic ${ }^{\mathrm{TM}}$ at each flow rate $\left(50-120 \mathrm{~L} \cdot \mathrm{min}^{-1}\right.$ in $10 \mathrm{~L} \cdot \mathrm{min}^{-1}$ intervals) and the data were graphically correlated to provide an estimate of flow measurements for each known pressure change. Pressure tracings were recorded during the challenge, on a chart recorder (Miniwriter Type WTR771A, Watanabe Instruments Corp., Tokyo, Japan) to provide instantaneous readings. The data was analysed more accurately after testing.

For the Inhalator ${ }^{\mathrm{TM}}$ the subjects were required to inhale the $\mathrm{NaCl}$ powder at a flow rate $>28 \mathrm{~L} \cdot \mathrm{min}^{-1}$. The inspired flow rate was checked by having the subject inhale maximally from the Inhalator ${ }^{\mathrm{TM}}$ while it was attached to an anemometer (Minato AS 800, Minato Medical Science Co Ltd, Osaka, Japan) prior to challenge on all of the test days. The best of three attempts was recorded. To calibrate the anemometer flows of 25-95 L. $\mathrm{min}^{-1}$ were generated through a rotameter (Series 2000, GEC-Elliott, Croydon, UK).

\section{Lung function measurements}

Spirometry was performed on an Autospiro AS-300 spirometer (Minato Medical Science Co Ltd., Osaka, Japan) and the FEV1 measurement was used as an index of change in airway calibre. The predicted FEV1 values used were taken from QuANJER et al. [15]. The spirometer was calibrated each morning using a $2 \mathrm{~L}$ syringe.

\section{Oxygen saturation}

Oxygen saturation $\left(\mathrm{Sa}_{\mathrm{a}} \mathrm{O}_{2}\right)$ was measured by oximetry (Ohmeda Biox 3700e, BOC Health Care, Louisville, CO, USA) as an index of safety. $\mathrm{Sa}_{\mathrm{a}} \mathrm{O}_{2}$ was measured during the dry $\mathrm{NaCl}$ capsule challenges in 22 subjects and for 11 subjects during the wet challenges.

\section{Challenge duration and number of capsules}

The median (and range) time taken to perform the challenge and the number of capsules used was calculated for the two devices.

\section{Study design}

Subjects were asked to attend the laboratory on four or five occasions with at least $48 \mathrm{~h}$ between visits. The first visit was a control day with a $4.5 \% \mathrm{NaCl}$ was challenge performed to determine eligibility for the study. Thereafter the subject performed either two dry powder $\mathrm{NaCl}$ capsule challenges (subjects 1-8) or a further wet aerosol followed by a further dry powder challenge (subjects 9-24).

\section{Wet aerosols of $4.5 \%$ sodium chloride challenge}

The sensitivity of the subjects to a wet aerosol of $4.5 \% \mathrm{NaCl}$ was measured on the control day visit. The aerosols was generated by a $\mathrm{MistO}_{2}$ gen EN 143a Ultrasonic Nebulizer (Timeter, PA, USA). Subjects inhaled the aerosols at resting ventilation rates through a twoway valve (No. 2700; Hans Rudolph, Kansas City, MO, USA) connected to the nebulizer by Bennetts smooth 
bore tubing (Cat. No. TV 2723) $67.5 \mathrm{~cm}$ in length with an internal diameter of $2.2 \mathrm{~cm}$. This unit was weighed with the tubing, but not the valve (Sartorius, $1216 \mathrm{MP}$, Gottingen, Germany), before the bronchial challenge and after the final dose of challenge aerosol had been delivered. Thus the output of the nebulizer over time was known for each subject on each occasion. The dose of wet aerosol delivered is expressed in milligrams of $\mathrm{NaCl}$. This value was obtained by multiplying the dose of aerosol delivered in grams by 45 (i.e. $45 \mathrm{mg} \mathrm{NaCl} \cdot \mathrm{g}$ aerosol delivered ${ }^{-1}$ ).

The protocol used to perform the challenge with $4.5 \%$ $\mathrm{NaCl}$ is described in detail by SMITH and Anderson [4], although the protocol was modified so that the maximum dose of aerosol delivered on the control day was greater than the usual dose of $15 \mathrm{~g}$. A further modification was made by measuring FEV1 in duplicate at only $60 \mathrm{~s}$ after each challenge period. This procedure was followed as the maximum response usually occurs within $1 \mathrm{~min}$ after each challenge interval.

Subjects inhaled the challenge aerosol for $0.5 \mathrm{~min}$ and waited $60 \mathrm{~s}$ before the FEV1 measurement was performed. If there was a $20 \%$ fall in FEV1 from the baseline value, the challenge was stopped and the subject included in the study. If a $20 \%$ fall was not recorded, the challenge continued for further exposures of $1,2,4,8,8$ and $8 \mathrm{~min}$ or part thereof, or ceased when a fall in FEV1 $\geq 20 \%$ was recorded. The subjects were eligible for the study if they had a $20 \%$ fall in FEV1 after $<22$ g of wet aerosol containing $990 \mathrm{mg}$ of $\mathrm{NaCl}$ had been delivered.

Following this challenge, subjects were given $0.5 \mathrm{mg}$ terbutaline sulphate via a pressurized metered dose inhaler actuated into a Nebuhaler ${ }^{\mathrm{TM}}$ (Astra Pharmaceuticals, Lund, Sweden).

\section{Dry powder $\mathrm{NaCl}$ challenge}

Subjects performed two challenges with dry powder $\mathrm{NaCl}$. Lung function, as measured by FEV1, was recorded on arrival at the laboratory, and 10 min later to establish its stability. The dose protocol consisted of inhaling 0 (empty capsule acting as a placebo) then 5 and/or 10 , then 20,40,80,160, 160 and $160 \mathrm{mg} \mathrm{NaCl}$. The doses of 40, 80 and 160 was given in multiples of either 20 or $40 \mathrm{mg}$ capsules. Two FEV1 manoeuvres were performed $60 \mathrm{~s}$ after the completion of each dose and the highest FEV1 measurement was used in calculations. The FEV1 value taken after the inhalation of the $0 \mathrm{mg}$ capsule was used to calculate the percentage fall in FEV1 in response to the dry $\mathrm{NaCl}$. If the subject had a fall $>10 \%$ in response to a single dose, then, for safety reasons the causative dose was repeated. The challenge was stopped when a $20 \%$ fall in FEV1 was measured or a total cumulative dose of $635 \mathrm{mg}$ had been given.

\section{Time course of recovery of lung function following chal- lenge}

Spontaneous recovery of FEV1 to baseline values (before any capsules were given) following the completion of the first capsule challenge was assessed in all subjects by performing spirometry $5 \mathrm{~min}$ after completion of the test, and then at $10 \mathrm{~min}$ intervals for at least
30 min or until the FEV1 had returned to within $5 \%$ of the baseline FEV1 value. Subjects $1-8$, following the completion of the second capsule challenge, received 0.5 $\mathrm{mg}$ terbutaline sulphate, actuated into and inhaled from a Nebuhaler ${ }^{\mathrm{TM}}$ and then performed spirometry $5 \mathrm{~min}$ later and at $10 \mathrm{~min}$ intervals for $30 \mathrm{~min}$, or until the subject had returned to within $5 \%$ of the baseline FEV1 value.

\section{Statistical analysis}

Baseline FEV1, expressed as a percentage of predicted normal, and post-placebo capsule percentage predicted FEV1 values were expressed as mean \pm SD and compared using an analysis of variance (ANOVA) and Student's paired t-test.

Airway sensitivity (PD20, $\mathrm{NaCl})$. Airway sensitivity was measured as the provoking dose of $\mathrm{NaCl}$ that caused a $20 \%$ fall in FEV1 (PD20,NaCl). These values were calculated by linear interpolation using the cumulative dose of $\mathrm{NaCl}$ causing a $20 \%$ fall in FEV1 from the pre-challenge value.

The geometric mean $(\mathrm{GM}) \pm 95 \%$ confidence interval ( $95 \%$ CI) and range of values were calculated for the $\mathrm{PD} 20, \mathrm{NaCl}(\mathrm{mg})$ values and the log PD20,NaCl values and compared using Students paired t-test for both inhaler devices and for the wet aerosol challenges. The Pearson correlation coefficient $\left(r_{p}\right)$ and significance values were calculated for the relationship between the $4.5 \%$ saline and the first and second $\mathrm{NaCl}$ capsule challenge for each of the two devices. The repeatability of the two $\mathrm{NaCl}$ capsule challenges was calculated using the log PD20, $\mathrm{NaCl}$. The equation previously described [16] was used to express repeatability as fold change. The data were also expressed in the manner described by BLAND and ALTMAN [17].

The ratio of the wet $\mathrm{PD} 20, \mathrm{NaCl}$ challenge:dry $\mathrm{PD} 20, \mathrm{NaCl}$ challenge was calculated to make a relative comparison between the two devices.

The peak inspiratory flow rates $\left(\mathrm{L} \cdot \mathrm{min}^{-1}\right)$ and duration of the challenge (min) were calculated for the Inhalator $^{\mathrm{TM}}(\mathrm{n}=8)$ and the Halermatic ${ }^{\mathrm{TM}}(\mathrm{n}=16)$ separately and expressed as median and range of values.

Student's paired t-test, was used to compare the spontaneous recovery values $(n=15)$ at 30 and $60 \mathrm{~min}$ and the recovery values following bronchodilator at 5 and $60 \mathrm{~min}$. For statistical and graphical reasons all values above the baseline FEV1 were considered to be 0 .

\section{Results}

\section{Pre-challenge lung function}

There was no significant difference for the baseline mean \pm SD FEV1 values expressed as the percentage of predicted FEV1 between any of the test days either within or between the two groups (table 2).

\section{Airway sensitivity to $\mathrm{NaCl}$}

Individual dose-response curves for the dry powder $\mathrm{NaCl}$ are illustrated for each device in figure 1 and the individual values for the wet and dry PD20, $\mathrm{NaCl}$ challenge are given in table 1 . The GM $(95 \% \mathrm{CI})$ for the 
Table 2. - Values obtained using the two different devices for inhalation of the dry powder of $\mathrm{NaCl}$

\begin{tabular}{|c|c|c|}
\hline & Inhalator ${ }^{\mathrm{TM}}$ & Halermatic ${ }^{\mathrm{TM}}$ \\
\hline Subject Nos. total & $1-8(8)$ & $9-24(16)$ \\
\hline Peak inspiratory flow $\mathrm{L} \cdot \mathrm{min}^{-1}$ & & \\
\hline median (range) & $58(46-65)$ & $65(38-103)$ \\
\hline Duration of challenge for $\mathrm{PD} 20, \mathrm{NaCl}$ median time $\min$ (range) & $10(6-15)$ & $13.5(3-38)$ \\
\hline Number of capsules median (range) & $6(3-11)$ & $5(2-17)$ \\
\hline First dry powder $\mathrm{NaCl}$ baseline $\mathrm{FEV} 1 \%$ pred $\pm \mathrm{SD}$ & $84 \pm 10 \%$ & $88 \pm 20 \%$ \\
\hline Second dry powder $\mathrm{NaCl}$ baseline $\mathrm{FEV} 1 \%$ pred $\pm \mathrm{SD}$ & $83 \pm 13 \%$ & $88.3 \pm 18 \%$ \\
\hline First dry powder $\mathrm{NaCl}$ geometric mean PD20 $(95 \% \mathrm{CI})$ & $80(46-138)$ & $117(64-212)$ \\
\hline Second dry powder $\mathrm{NaCl}$ geometric mean $\mathrm{PD} 20(95 \% \mathrm{CI})$ & $84(45-156)$ & $123(77-196)$ \\
\hline First wet aerosol $4.5 \% \mathrm{NaCl}$ baseline $\mathrm{FEV} 1 \%$ pred $\pm \mathrm{SD}$ & $83 \pm 16 \%$ & $87 \pm 19 \%$ \\
\hline Second wet aerosol $4.5 \% \mathrm{NaCl}$ baseline $\mathrm{FEV} 1 \%$ pred $\pm \mathrm{SD}$ & - & $90 \pm 17 \%$ \\
\hline First wet aerosol $4.5 \% \mathrm{NaCl}$ geometric mean PD20 (95\% CI) & $274(137-550)$ & $213(117-385)$ \\
\hline Second wet aerosol $4.5 \% \mathrm{NaCl}$ geometric mean PD20 (95\% CI) & - & $253(139-459)$ \\
\hline Pearson's correlation $\left(\mathrm{r}_{\mathrm{p}}\right)$ wet versus dry & 0.53 & 0.61 \\
\hline \multicolumn{3}{|l|}{ Repeatability fold change $95 \%$ CI } \\
\hline dry powder $\mathrm{NaCl}$ & $0.3-1.8$ & $0.6-1.5$ \\
\hline wet aerosol $\mathrm{NaCl}$ & - & $0.7-1.7$ \\
\hline
\end{tabular}

PD20: provocative dose causing a $20 \%$ fall in forced expiratory volume in one second (FEV1); $\%$ pred: percentage of predicted value; $95 \%$ CI: $95 \%$ confidence interval.
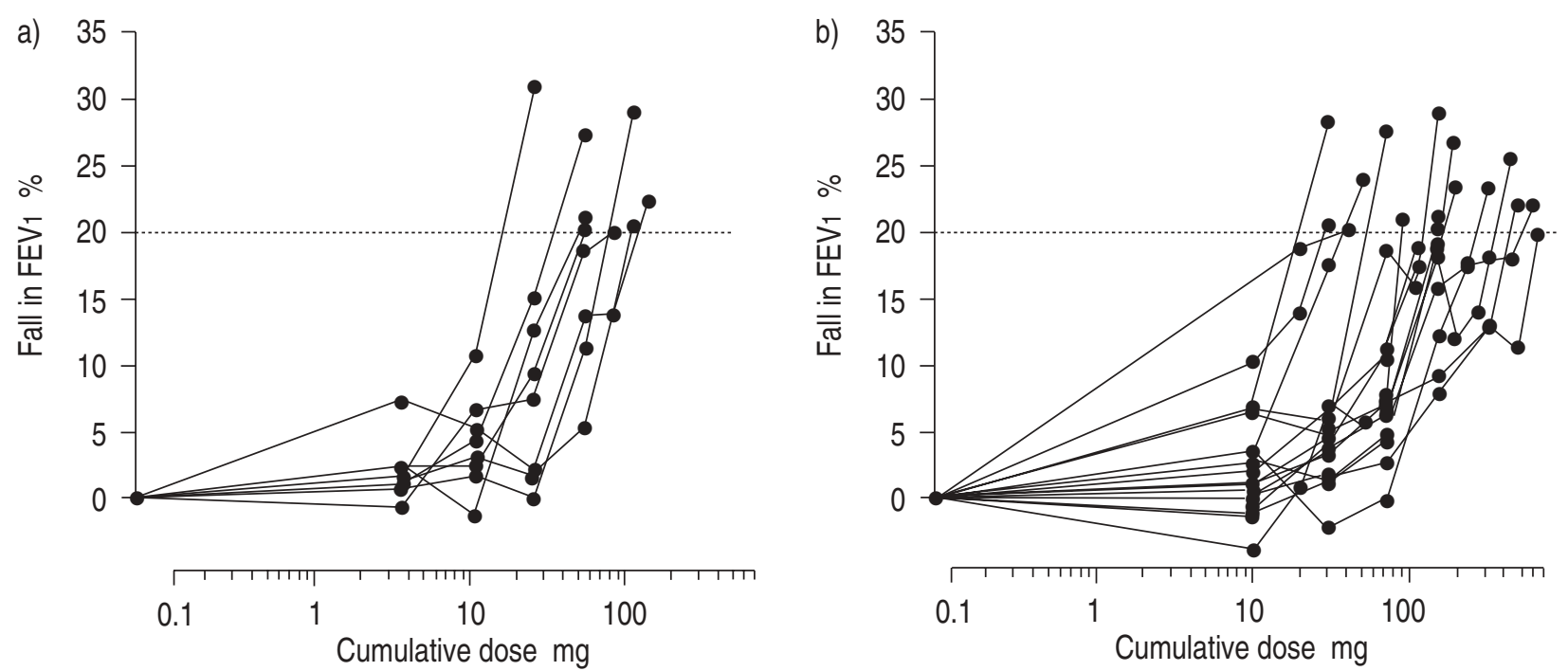

Fig. 1. - Individual dose-response curves for a) the eight subjects who inhaled from the Inhalator ${ }^{\mathrm{TM}}$ and $\mathrm{b}$ ) the 16 asthmatics who inhaled from the Halermatic ${ }^{\mathrm{TM}}$. The provoking dose of dry powder $\mathrm{NaCl}$ causing a $20 \%$ reduction in FEV1 (PD20) in the 24 asthmatic subjects represented a wide range in severity of airway responsiveness. FEV1: forced expiratory volume in one second.

$\mathrm{PD} 20, \mathrm{NaCl}$ for both the $4.5 \%$ saline challenge and the dry powder challenges for the two devices is given in table 2. The relationship between the values for PD20,NaCl on the initial wet and dry challenges for the whole group was $r_{p}=0.55, p<0.01$ (fig. 2) and is given separately for the two inhalers in table 2. The relationship between the values for $\mathrm{PD} 20, \mathrm{NaCl}$ on the initial dry challenge and the second wet challenge for the 15 subjects who performed two wet challenges was $r_{p}=0.61, p<0.05$. The ratio of wet PD20, $\mathrm{NaCl}$ challenge:dry $\mathrm{PD} 20, \mathrm{NaCl}$ challenge was $2.55(0.14-8.87)$ for the Inhalator ${ }^{\mathrm{TM}}$ and $3.12(0.4-20.1)$ for the Halermatic ${ }^{\mathrm{TM}}$. These values were not significantly different.

There was no significant difference in values for PD20, $\mathrm{NaCl}$ measured between repeated challenges either for the wet or the dry aerosol (table 2). The repeatability expressed as fold-change is given in table 2, and expressed as a Bland and Altman plot as illustrated in figure 3 .

\section{Oxygen saturation during challenge}

The initial challenge value and the lowest saturation value measured were used to calculate the fall in saturation during challenge. The $S \mathrm{a}_{2} \mathrm{O}_{2}$ was measured in 11 of the 24 subjects during the wet $\mathrm{NaCl}$ aerosol challenge. The lowest $\mathrm{Sa}, \mathrm{O}_{2}$ during the wet challenge was $95 \%$ and none of the subjects fell more than $2 \%$. During the first dry capsule two subjects had no $\mathrm{Sa}_{\mathrm{a}} \mathrm{O}_{2}$ measurements. Of the remaining 22 subjects, two fell by $3 \%$ during challenge and one fell by $6 \%$. The lowest $\mathrm{Sa}_{\mathrm{a}} \mathrm{O}_{2}$ measured during dry $\mathrm{NaCl}$ capsule challenge was $92 \%$ (recorded for the subject who fell 6\%). The remaining 19 subjects fell less than $3 \%$ during challenge. During the second dry capsule challenge three of the 24 subjects fell $3 \%$ and the remaining 21 subjects fell less than $3 \%$ during challenge. The lowest $\mathrm{Sa}_{\mathrm{a}} \mathrm{O}_{2}$ recorded during the second challenge was $94 \%$ which may be considered "normal" or just below. 


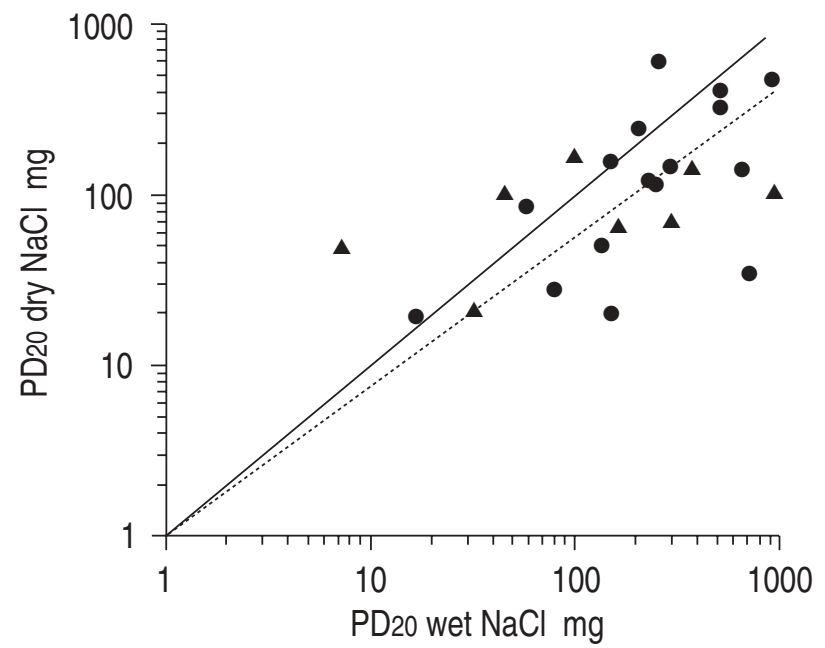

Fig. 2. - Individual values obtained for the provoking dose delivered in milligrams of the wet aerosol of $4.5 \% \mathrm{NaCl}$ to induce a $20 \%$ fall in forced expiratory volume in one second (wet challenge PD20) in relation to the PD20 obtained for the dry powder preparation. $\mathbf{\Delta}$ : subjects who inhaled from the Inhalator ${ }^{\mathrm{TM}}$; $:$ subjects who inhaled from the Halermatic ${ }^{\mathrm{TM}}$._ : line of identity; ………..... : line of correlation $\left(\mathrm{r}_{\mathrm{p}}=0.55, \mathrm{p}<0.01, \mathrm{n}=24\right)$. The PD20 for the dry powder was significantly less compared with the wet aerosol although eight of the 24 subjects required a greater dose when the dry powder was used.

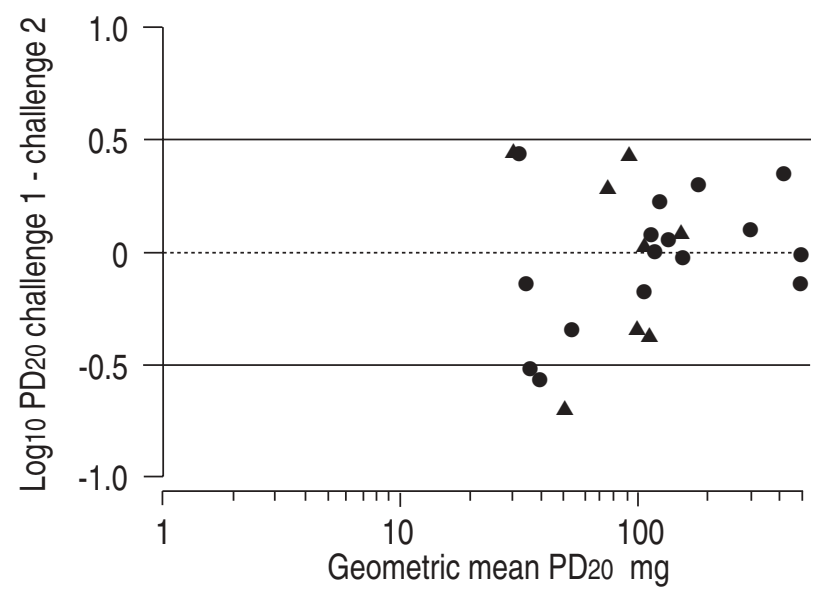

Fig. 3. - A Bland and Altman plot relating the geometric mean for the provoking dose of $\mathrm{NaCl}$ causing a $20 \%$ fall in forced expiratory volume in one second (FEV1) (PD20) for the first and second challenge with dry powder $\mathrm{NaCl}$ plotted against the difference between the $\log 10$ PD20 values for the 24 subjects who performed repeated challenge. $\mathbf{\Delta}$ : subjects who inhaled from the Inhalator ${ }^{\mathrm{TM}} ; \bullet$ : subjects

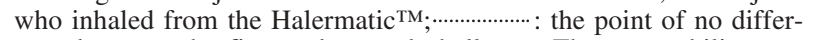
ence between the first and second challenge. The repeatability was independent of the dose. The difference in $\log 10$ PD20 values for all but two subjects was \pm 0.5 .

\section{Peak inspiratory flow rate (PIFR)}

The median values for the PIFR measured for both dry powder devices are given in table 2 . PIFR exceeded $38 \mathrm{~L} \cdot \mathrm{min}^{-1}$ in all subjects.

\section{Aerosol characteristics of powder preparations and devices}

For the initial powder preparation the analysis of the particle size, using the Halermatic ${ }^{\mathrm{TM}}$, revealed that $<7 \%$ of the $\mathrm{NaCl}$ was in the respirable range of $\leq 7 \mu \mathrm{m}$ by the time it had reached Sydney, although at the time of preparation in California 19\% was in the respirable range.
This initial batch was unsuccessful in provoking an airway response when delivered by a Halermatic ${ }^{\mathrm{TM}}$. The second batch of dry powder had $37 \%$ of particles below $7 \mu \mathrm{m}$ at the time of preparation and $30 \%$ at the time of use in Sydney when measured with the Halermatic ${ }^{\mathrm{TM}}$ and this was used successfully in subjects 9-24. The third batch received a year later was also a failure going from $38 \%$ at source to $13 \%$ at the time of use in Sydney. The fourth batch had $15.8 \%$ of the mass below $7 \mu \mathrm{m}$ and was used successfully when inhaled from the Inhalator ${ }^{\mathrm{TM}}$.

\section{Challenge duration and number of capsules}

The median duration of the challenge and number of capsules used is given in table 2 .

\section{Recovery following dry powder $\mathrm{NaCl}$ capsule challenge}

Spontaneous recovery was analysed in 23 subjects following the first $\mathrm{NaCl}$ challenge. Subject No. 16 was not included in the analysis as she did not spontaneously recover and required the administration of bronchodilator at $30 \mathrm{~min}$. For $\mathrm{n}=23$ at $30 \mathrm{~min}$ post-challenge the mean \pm SD percentage reduction from baseline FEV 1 was still $-15 \pm 8.8 \%$ but at $60 \mathrm{~min}$ it was only $-7 \pm 5.4 \%$ below baseline. That is, the FEV1 had returned spontaneously to $93 \%$ of the baseline value 60 min after challenge.

Recovery after the first capsule challenge following bronchodilator was compared to spontaneous recovery in the eight subjects who used the Inhalator ${ }^{\mathrm{TM}}$ (fig. 4). Five minutes after the bronchodilator had been given the mean \pm SD percentage change from baseline FEV1 following bronchodilator was $-5 \pm 5.8 \%$ compared to $-22 \pm 6.5 \%$ without bronchodilator $(\mathrm{n}=8, \mathrm{p}<0.003)$. At $60 \mathrm{~min}$ the

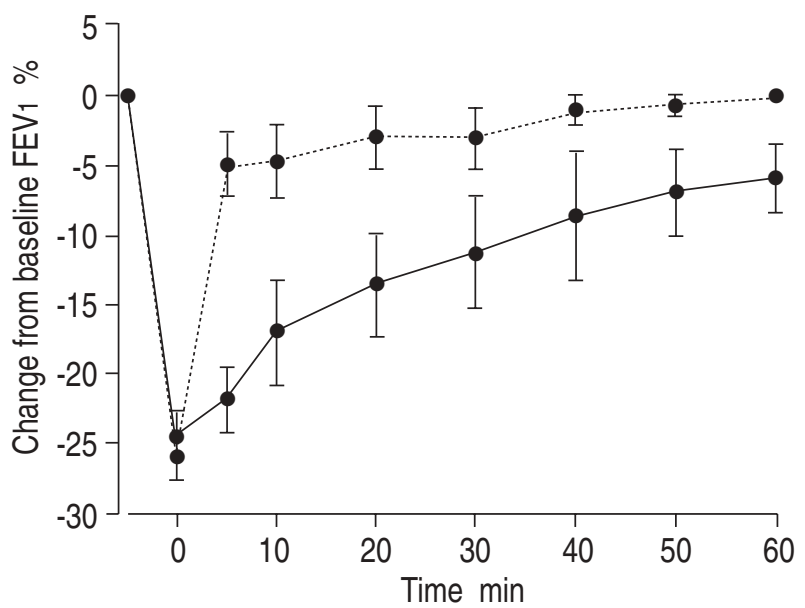

Fig. 4. - The mean \pm SEM for the forced expiratory volume in one second (FEV1) expressed as a percentage reduction from the baseline prechallenge value in the eight subjects who spontaneously recovered after the first challenge with dry powder sodium chloride ( - ) and were given $0.5 \mathrm{mg}$ of terbutaline aerosol immediately after the second challenge $(\ldots \ldots \ldots \ldots \ldots . . . . .$.$) . The value at time 0$ was the maximum reduction in FEV1 recorded and the time after bronchodilator or spontaneous recovery is shown. For seven of the eight subjects the FEV 1 had returned to within $6 \%$ of baseline within 5 min after taking bronchodilator. There was a significant difference in the values for FEV 1 5 min after bronchodilator had been administered $(\mathrm{p}<0.003)$. For the remaining subject recovery took $50 \mathrm{~min}$. 
subjects who had received bronchodilator had all returned to baseline whereas those who recovered spontaneously had an FEV1 compared with baseline of $-6 \pm 6.8 \%(n=8$, $\mathrm{p}=0.05$ ).

\section{Healthy control subjects}

Five healthy control subjects (aged 19-22 yrs) performed an inhalational challenge using the dry powder $\mathrm{NaCl}$ administered from the Halermatic ${ }^{\mathrm{TM}}$ device. Four received a dose of $620 \mathrm{mg}$ and one a dose of $540 \mathrm{mg}$. None of these healthy volunteers, who acted as control subjects, recorded a $\mathrm{PD} 20, \mathrm{NaCl}$ and the maximum fall in FEV1 was $6.5 \%$ with the range being $0-6.5 \%$.

\section{Discussion}

In this study we have shown that a dry powder preparation of $\mathrm{NaCl}$, delivered from a capsule via either a Halermatic $^{\mathrm{TM}}$ or an Inhalator ${ }^{\mathrm{TM}}$ device, can provoke airway narrowing in the same asthmatic subjects who are sensitive to the wet aerosol preparation of $4.5 \% \mathrm{NaCl}$. Furthermore, the airway response to the dry powder had good repeatability and spontaneous recovery from the challenge occurred over $60 \mathrm{~min}$. With the aid of a bronchodilator FEV1 recovered to $95 \%$ of the baseline value in less than $10 \mathrm{~min}$.

The wet aerosol was always performed first on the control day because the entry criteria required that. However, the difference in $\mathrm{PD} 20, \mathrm{NaCl}$ values for the first dry challenge and either the first or the second wet challenge was similar, suggesting that there was no order effect.

In order to evaluate the dry powder we used subjects who had a wide variation in their wet PD20, $\mathrm{NaCl}$ and two different devices. Thus, the subject who was most sensitive to the $4.5 \% \mathrm{NaCl}$ wet aerosol required less than $30 \mathrm{~s}$ exposure with a $\mathrm{PD} 20, \mathrm{NaCl}$ of $7 \mathrm{mg}$ while the least sensitive subject required 22 min exposure and had a PD20, $\mathrm{NaCl}$ of $955 \mathrm{mg}$. A PD20, $\mathrm{NaCl}$ of less than $90 \mathrm{mg}$ is regarded as consistent with severe bronchial responsiveness, 90-270 $\mathrm{mg}$ as moderate and greater than 270 $\mathrm{mg}$ as mild responsiveness to wet $\mathrm{NaCl}$ challenge [5]. All our asthmatic subjects displayed the expected airway response and none of the healthy subjects responded. Healthy nonasthmatic subjects do not demonstrate bronchial responsiveness to $4.5 \%$ saline and the mean \pm SD percentage reduction from baseline FEV1 for a group of 75 people has been previously reported as $4.6 \pm 3.1 \%$ [5]. The limited number of healthy control subjects investigated in this study related to the limited availability of dry powder.

The two inhalers used were selected because they were both commercially available. However, their characteristics were different in the way in which the capsules were pierced and the powder dispersed and they had differing inspiratory resistances (low for the Halermatic $^{\mathrm{TM}}$ and high for the Inhalator $\left.{ }^{\mathrm{TM}}\right)$. The airway responses to dry $\mathrm{NaCl}$ were not compared in the same subjects using both devices, because only a small amount of dry $\mathrm{NaCl}$ was available and 12 months separated the two studies. However there did not appear to be any qualitative differences between the devices, as evident from the individual dose-response curves. While there were some differences between the PD20, $\mathrm{NaCl}$ for the two devices this was more likely to have been related to the severity of their asthma, as their responses to the wet aerosol were similarly smaller. Furthermore, the ratio of the wet PD20, $\mathrm{NaCl}$ :dry PD20, $\mathrm{NaCl}$ was similar for both devices. The values observed for repeatability on the Halermatic $^{\mathrm{TM}}$ were somewhat better than the Inhalator ${ }^{\mathrm{TM}}$ but this may have been due to the small numbers of subjects studied on the Inhalator ${ }^{\mathrm{TM}}$. Both devices were adequate for the delivery of the salt although the Inhalator was easier to use because it pierced the capsules more easily. We also found that the Inhalator ${ }^{\mathrm{TM}}$ caused less cough compared with the Halermatic ${ }^{\mathrm{TM}}$. This may be because of the higher inspiratory resistance of the Inhalator ${ }^{\mathrm{TM}}$, resulting in less deposition of the powder on the back of the throat.

We do not know where in the respiratory tract the $\mathrm{NaCl}$ was deposited or what percentage of the inhaled dose was deposited in the lower respiratory tract. The relatively small changes in $\mathrm{Sa}_{\mathrm{a}} \mathrm{O}_{2}$, in most subjects, suggest that the site of deposition of the $\mathrm{NaCl}$ was more likely to be the larger airways. Further studies with labelled $\mathrm{NaCl}$ are required to determine the ratio of peripheral to central deposition of the powder in the airways [18].

We have measured the size of the wet aerosol particles of the $\mathrm{NaCl}$ after passing through the tubing and valve to $3.6 \mu \mathrm{m}$ with a geometric SD less than 1.1 [19]. We have also measured the amount of wet aerosol reaching the mouth as $47 \%$ of that reaching the inspiratory port of the two-way valve [5]. On the basis of these measurements we have estimated the volume of wet aerosol reaching the lower respiratory tract to be approximately $10 \%$ of the volume generated by the nebulizer [5]. This is a value similar to that which has been measured for jet nebulizers [20]. The percentage of particles of dry powder of $\mathrm{NaCl}$ less than $7 \mu \mathrm{m}$ measured at the site of testing was $15.8 \%$ for the Inhalator ${ }^{\mathrm{TM}}$ and $30 \%$ for the Halermatic ${ }^{\mathrm{TM}}$. It is possible that a higher proportion of the dry powder aerosol entered the lower respiratory tract with the Inhalator ${ }^{\mathrm{TM}}$ compared with the Halermatic $^{\mathrm{TM}}$ [21] but we have no in vivo data on deposition.

For $50 \%$ of the subjects, the dose required to record a $\mathrm{PD} 20, \mathrm{NaCl}$ was less than $100 \mathrm{mg}$ when the dry powder was used. For one subject with very mild asthma, receiving 1,200 $\mu \mathrm{g} \cdot \mathrm{day}^{-1}$ of the aerosol corticosteroid budesonide, a cumulative dose of $493 \mathrm{mg}$ was required, but this was reproducible with $503 \mathrm{mg}$ being required on the second challenge. This was substantially less than the dose required by wet aerosol in the same subject. However there were three subjects who required substantially more dry powder than wet aerosol. Some subjects showed much greater variation in their PD20, $\mathrm{NaCl}$ on the two test days. However, the repeatability for the dry powder compared well with the repeatability for wet aerosol challenge performed in the same subjects. Furthermore, the repeatability compares well with other challenge tests such as histamine or methacholine [22, 23].

There were no adverse experiences requiring medical intervention with the dry powder. The $\mathrm{Sa}_{\mathrm{a}} \mathrm{O}_{2}$ as measured 
by ear oximetry remained above $94 \%$ in all but one subject. Three subjects did gag with the $40 \mathrm{mg}$ dose but even with this there was no significant fall in their $\mathrm{Sa}_{\mathrm{a}} \mathrm{O}_{2}$. We were not required to give bronchodilator immediately at the end of challenge in any subject. One subject was given a bronchodilator $30 \mathrm{~min}$ after challenge on the day spontaneous recovery was being documented. The dry $\mathrm{NaCl}$ powder was well tolerated at the lower doses but with the $40 \mathrm{mg}$ capsule some subjects found difficulty with inhaling quickly and coughed. The coughing could have reduced deposition and be the reason that some subjects required a much higher dose of dry $\mathrm{NaCl}$ compared with the wet $\mathrm{NaCl}$ aerosol. Furthermore, it is possible that the dry powder provided a potent pharyngeal stimulus contributing to the airway narrowing by causing reflex bronchoconstriction.

From our studies using the liquid impinger we had $40-70 \%$ recovered on the "throat" and Stage 1 (particles above $13 \mu \mathrm{m}$ ) This is probably the reason that many patients coughed while inspiring the $40 \mathrm{mg}$ capsules. Ideally a greater percentage of the dose would have a particle size in the respirable range. Indeed the most important issue relating to this study was the reliability and stability of the dry powder preparations. We received four batches of $\mathrm{NaCl}$ from California and only two of these were used successfully in Sydney. Further studies are required to establish the long-term stability of the powder preparation before studies are performed on sensitivity and specificity of the challenge in large numbers of subjects.

The precise mechanism whereby hyperosmolarity leads to airway narrowing is not known. At present it is thought that mast cell mediators [9, 24-26] and neuropeptides from sensory nerves are released in response to this stimulus. The evidence to support this contention comes from in vitro and in vivo studies. An increase in osmolarity is a potent stimulus for human lung mast cell release of histamine [27] and in humans the airway responses to hyperosmolarity are markedly inhibited by specific antihistamines [28, 29]. The only evidence in support of neuropeptide comes from work in animals. It shows indirectly that $\mathrm{C}$-fibres are stimulated by hyperosmolarity and there is an increase in microvascular permeability that can be accounted for by the release of neuropeptides [30, 31].

We believe that hypertonic saline challenge is an attractive alternative to the pharmacological challenges with histamine and methacholine that are currently used most widely, both in routine hospital laboratories [1, $32]$ and in the field of epidemiology [22, 23, 33, 34]. We consider that the hypertonic saline challenge is not only useful for identifying persons with asthma, but will be particularly important in following response to treatment with aerosol corticosteroids $[35,36]$. We predict that the advantage in using a hypertonic challenge in epidemiology is in its high specificity yet comparable sensitivity to other challenge tests to identify current asthma [6, 8, 37]. We believe that a hypertonic challenge test would adapt well to use outside the hospital laboratory if an appropriate dry powder preparation of an osmotic agent could be found.

There are many potential advantages in using dry powders for delivering substances used for bronchial provocation testing. One advantage is the reduced exposure of the test aerosol to the investigator. Another is the safe disposable nature of the device and the substance. There would be considerable time saved in using dry powders compared with wet aerosol preparations in that the equipment used for nebulization and to determine output is expensive and requires cleaning and regular maintenance.

This is the first report of the airway narrowing effects of dry particles of sodium chloride in known asthmatic subjects. The challenge with sodium chloride would appear as safe as any other challenge with which we have had experience, i.e. methacholine, histamine, exercise and hyperventilation. Further studies are required to establish safety and efficacy and acceptability in larger groups of subjects and to compare responses with other stimuli commonly used for bronchial provocation testing. From a technical standpoint, long-term stability of the dry powder of sodium chloride and achieving a greater proportion of substance in the respirable range (to reduce coughing) are important issues that need to be addressed before commercial development is considered.

\footnotetext{
Acknowledgements: The authors would like to thank G. King and I. Young for their medical assistance and J. Brannan for analysis of the results.
}

\section{References}

1. Sterk PJ, Fabbri LM, Quanjer PhH, et al. Airway responsiveness: standardized challenge testing with pharmacological, physical and sensitizing stimuli in adults. Eur Respir J 1993; 6: Suppl. 16, 53-83.

2. Schoeffel RE, Anderson SD, Altounyan RE. Bronchial hyperreactivity in response to inhalation of ultrasonically nebulised solutions of distilled water and saline. Br Med J 1981; 283: 1285-1287.

3. Anderson SD, Schoeffel RE, Finney M. Evaluation of ultrasonically nebulised solutions as a provocation in patients with asthma. Thorax 1983; 38: 284-291.

4. Smith CM, Anderson SD. Inhalation provocation tests using non-isotonic aerosols. J Allergy Clin Immunol 1989; 84: 781-790.

5. Anderson SD, Smith CM, Rodwell LT, du Toit JI, Riedler J, Robertson CF. The use of non-isotonic aerosols for evaluating bronchial hyperresponsiveness. In: Spector S, ed. Provocation Challenge Procedures. New York, Marcel Dekker, 1995; pp. 249-278.

6. Araki H, Sly P. Inhalation of hypertonic saline as a bronchial challenge in children with mild asthma and normal children. J Allergy Clin Immunol 1989; 84: 99-107.

7. Riedler J, Reade T, Robertson CF. Repeatability of the response to $4.5 \% \mathrm{NaCl}$ challenge in children with mild to severe asthma. Pediatr Pulmonol 1994; 18: 330-336.

8. Riedler J, Reade T, Dalton M, Holst DI, Robertson CF. Hypertonic saline challenge in an epidemiological survey of asthma in children. Am J Respir Crit Care Med 1994; 150: 1632-1639.

9. Smith CM, Anderson SD. Inhalational challenge using hypertonic saline in asthmatic subjects: a comparison with responses to hyperpnoea, methacholine, and water. Eur Respir J 1990; 3: 144-151.

10. Belcher NG, Lee TH, Rees PJ. Airway responses to hypertonic saline, exercise and histamine challenges in bronchial asthma. Eur Respir J 1989; 2: 44-48. 
11. Boulet L-P, Turcotte H. Comparative effects of hyperosmolar saline inhalation and exercise in asthma. Immunol Allergy Practice 1989; 11: 93-100.

12. Pedersen S, Steffersen G. Fenoterol powder inhaler technique in children: influence of inspiratory flow rate and breatholding. Eur J Respir Dis 1986; 68: 207-214.

13. Fahy D, Meakin B, Ganderton G, Millar AB. Do changes in peak inspiratory flow occur with inspiration through dry powder inhalers? Thorax 1993; 48: 460.

14. Vidgren MT, Karkkainen A, Karjalainen P, Paronen P, Nuutinen J. Effect of powder inhaler design on drug deposition in the respiratory tract. Int J Pharm 1988; 41: 211-216.

15. Quanjer PhH, Tammeling GJ, Cotes JE, Pederson OF, Peslin R, Yernault J-C. Lung volumes and forced ventilatory flows. Eur Respir J 1993; 6: Suppl 16, 5-40s.

16. Peat JK, Unger WR, Combe D. Measuring changes in logarithmic data, with special reference to bronchial responsiveness. J Clin Epidemiol 1994; 47: 1099-1108.

17. Bland JM, Altman DG. Statistical methods for assessing agreement between two methods of clinical measurement. Lancet 1986; i: 307-310.

18. Phipps PR, Gonda I, Bailey DL, Borham P, Bautovich $\mathrm{G}$, Anderson SD. Comparisons of planar and tomographic gamma scintigraphy to measure the penetration index of inhaled aerosols. Am Rev Respir Dis 1989; 139: $1516-1523$.

19. Rodwell LT. The role of hyperosmolar challenge in the assessment and treatment of asthma. $\mathrm{PhD}$ Thesis, University of Sydney, 1994

20. Shenfield GM, Evans ME, Paterson JW. The effect of different nebulizers with and without intermittent positive pressure breathing on the absorption and metabolism of salbutamol. Br J Clin Pharmacol 1974; 1: 295-300.

21. Newman SP, Hollingworth A, Clark AR. Effect of different modes of inhalation on drug delivery from a dry powder inhaler. Int J Pharm 1994; 102: 127-132.

22. Peat JK, Salome CM, Bauman A, Toelle BG, Wachinger SL, Woolcock AJ. Repeatability of histamine bronchial challenge and comparability with methacholine bronchial challenge in a population of Australian schoolchildren. Am Rev Respir Dis 1991; 144: 338-343.

23. Chinn S, Britton JR, Burney PGJ, Tattersfield AE, Papacosta AO. Estimation and repeatability of the response to inhaled histamine in a community survey. Thorax 1987; 42: 45-52

24. Gravelyn TR, Pan PM, Eschenbacher WL. Mediator release in an isolated airway segment in subjects with asthma. Am Rev Respir Dis 1988; 137: 641-646.
25. Belcher NG, Murdoch RD, Dalton N, et al. A comparison of mediator and catecholamine release between exercise- and hypertonic saline-induced asthma. Am Rev Respir Dis 1988; 137: 1026-1032.

26. Maxwell DL, Hawkesworth RJ, Lee TH. Effect of nedocromil sodium on histamine release from isolated large airway segments of asthmatic subjects in vivo. Eur Respir J 1993; 6: 1145-1150.

27. Eggleston PA, Kagey-Sobotka A, Schleimer RP, Lichtenstein LM. Interaction between hyperosmolar and IgEmediated histamine release from basophils and mast cells. Am Rev Respir Dis 1984; 130: 86-91.

28. Finney MJB, Anderson SD, Black JL. Terfenadine modifies airway narrowing induced by the inhalation of nonisotonic aerosols in subjects with asthma. Am Rev Respir Dis 1990; 141: 1151-1157.

29. Rodwell LT, Anderson SD, Seale JP. Inhaled clemastine inhibits airway narrowing caused by aerosols of non-isotonic saline. Eur Respir J 1991; 4: 1126-1134.

30. Pisarri TE, Jonson A, Coleridge HM, Coleridge JCG. Intravenous injection of hypertonic $\mathrm{NaCl}$ solutions stimulates pulmonary C-fibres in dogs. Am J Physiol 1991; 260 (Heart Circ Physiol 29): H1522-1530.

31. Umeno E, McDonald OM, Nadel JA. Hypertonic saline increases vascular permeability in the rat trachea by producing neurogenic inflammation. J Clin Invest 1990; 851: 1905-1908.

32. Scott GC, Braun SR. A survey of the current use and methods of analysis of bronchial provocational challenges. Chest 1991; 100: 322-328.

33. Toelle BG, Peat JK, Salome CM, Mellis CM, Woolcock AJ. Toward a definition of asthma for epidemiology. Am Rev Respir Dis 1992; 146: 633-637.

34. Juniper EF, Kline PA, Vanzieleghem MA, Ramsdale EH, O'Byrne PM, Hargreave F. Effect of long-term treatment with inhaled corticosteroids on airway hyperresponsiveness and clinical asthma in non-steroid dependent asthmatics. Am Rev Respir Dis 1990; 142: 832-836.

36. Anderson SD, du Toit JI, Rodwell LT, Jenkins CR. The acute effect of sodium cromoglycate on airway narrowing induced by $4.5 \%$ saline in asthmatic patients, before and during treatment with aerosol corticosteroids. Chest 1994; 105: 673-680.

35. Rodwell LT, Anderson SD, Seale JP. Inhaled steroids modify bronchial responses to hyperosmolar saline. Eur Respir J 1992; 5: 953-962.

37. Rabone S, Phoon WO, Anderson SD, et al. Hypertonic saline bronchial challenge in adult epidemiological field studies. Occup Med 1996; 46: 177-185. 